\title{
Growth and optical properties of dye films and dye-in-polymer matrix deposited by vacuum evaporation
}

\author{
K. Grytsenko ${ }^{1 *}$, T. Doroshenko ${ }^{1}$, Yu. Kolomzarov ${ }^{1 *}$, O. Lytvyn ${ }^{1 *}$, M. Serik², \\ O. Tolmachev ${ }^{3 *}$, Yu. Slominski ${ }^{3}$, S. Schrader ${ }^{4}$ \\ ${ }^{I}$ V. Lashkaryov Institute of Semiconductor Physics, NAS of Ukraine, Kyiv, Ukraine, \\ ${ }^{2}$ T. Shevchenko Kyiv National University, Ukraine, \\ ${ }^{3}$ Institute of Organic Chemistry, NAS of Ukraine, Kyiv, Ukraine, \\ ${ }^{4}$ University of Applied Sciences Wildau, Germany \\ *Corresponding authors: phone/fax: +38044 5255530 e-mail: d.grytsenko@gmail.com, Tompavl54@gmail.com, \\ Kolomzarov@yahoo.com,olytvyn@isp.kiev.ua
}

\begin{abstract}
Searching new more effective materials for organic electroluminescent displays is continuing. The polymethine dyes is a class of organic materials that are very interesting for these purposes. Films of the polymethine dyes were deposited by evaporation in vacuum. Also deposited were dye-filled polytetrafluoroethylene (PTFE) films. Kinetics of growth and heating the films were observed using optical spectroscopy in situ. It was found out the influence of the chemical structure of dyes on growth and heating kinetics of the dye films. It was found that PTFE matrix strongly enhances dye stability.
\end{abstract}

Keywords: polymethine dye, thin film, vacuum deposition, optical spectroscopy.

Manuscript received 28.12.09; accepted for publication 25.03.10; published online 30.04.10.

\section{Introduction}

Polymethine dyes (PMD) are able to sensitize various photoprocesses, their thin films can be used in sensors, nonlinear optics, optoelectronics, electroluminescent devices [1]. PMD are characterized by main influence of intermolecular interactions on formation of dye solid crystal structure, so they are able to form organized thin films with three possible types of aggregates. Therefore, recently the researches in the field of deposition, structure and optical properties of PMD were carried out $[2,3]$. The most complete information about the growth process of a dye film can be obtained using optical absorption spectroscopy in situ [4]. Recently we found that polytetrafluoroethylene (PTFE) matrix influences on the properties of dye clusters [5-7].

The aim of our researches was to study structural transformations during growth and heating the novel PMD films, the influence of PTFE sublayer and matrix on these processes.

\section{Experimental details}

Films were deposited using VUP-5 and UVN-74 (USSR) installations equipped with optical spectrometers Stellar Net and Polytec. Rotating glass discs with attached glass and silica slides were used as substrates. PTFE was evaporated with vapor activation by electron cloud. Heated boat was used for PMD evaporation. Details can be found elsewhere $[5,6]$. Heated not rotated glass and PTFE substrates were used for PMD deposition as well. Annealing the films was made in home-made oven equipped with optical spectrometer Polytec for spectra recording in situ. Film morphology was studied by atomic force microscope (AFM) Nanoscope IIIa Dimension $3000^{\mathrm{TM}}$ at room temperature. Pure thin films or dyes were successfully fabricated at the deposition rate of 0.1-1.6 E/s, when the sample was heated at 200 to $350{ }^{\circ} \mathrm{C}$ under the residual pressure $5 \times 10^{-3} \mathrm{~Pa}$.

\section{Experimental results and discussion}

The rows of three kinds of PMD with varying substituents were synthesized $(1-2400,2401,2403$, 2404, 2406; 2 - 2427, 2495, 2496, 2498; 3 - 7496, 7482, 7488, 7483, 7476, 7477 and 7497). Chemical formulas for the most interesting PMDs are shown in Fig. 1. The comparison of the spectra of original PMD solutions and washed out PMD film solutions in dichlormethane proved that PMD molecules were not degraded during thermal evaporation. 
<smiles>CN1/C(=C/C2=Nc3cccc4cccc2c34)Sc2ccccc21</smiles><smiles>CN1C=CC(=CC=C2C=C(C(C)(C)C)C(=O)C(C(C)(C)C)=C2)c2ccccc21</smiles>

Fig. 1. Chemical formulas of polymethine dyes.
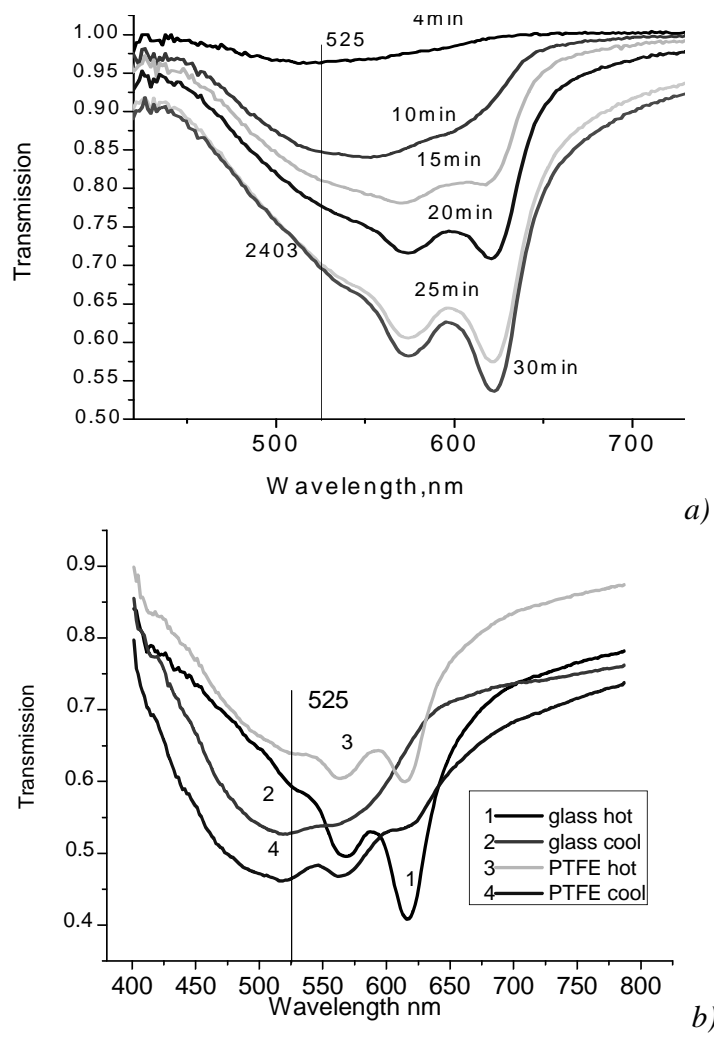

Fig. 2. Optical changes in 2403 PMD films: (a) during growth on glass, time dependence; (b) by influence of substrate material and its temperature.

In Fig. 2a, optical changes during growth of the 2403 PMD film on glass are shown; in Fig. $2 b$ influence of substrate material and its temperature on 2403 films is shown. AFM picture (Fig. 3a) shows that during deposition first uniform structure with PMD molecules in the monomeric state was formed, then needle-like aggregates appeared with increasing the film thickness.

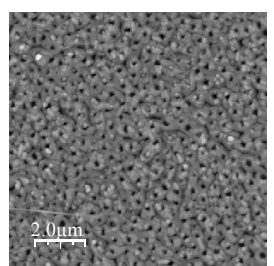

2403 thin

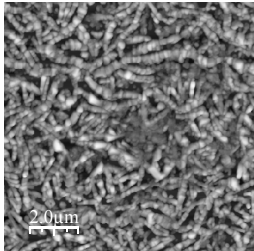

2403 thick

a)

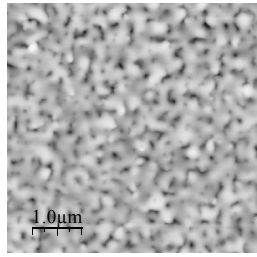

2403 on PTFE
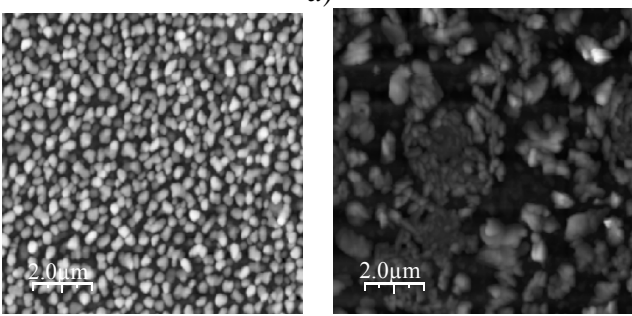

2403 on oriented PTFE

$20^{\circ} \mathrm{C}$

b)

Fig. 3. AFM images of 2403 film surface: (a) thin and thick films on glass, corresponding to spectra 2403 in Fig. 2a; (b) on oriented PTFE, corresponding to spectra 2403 in Fig. $2 b$.

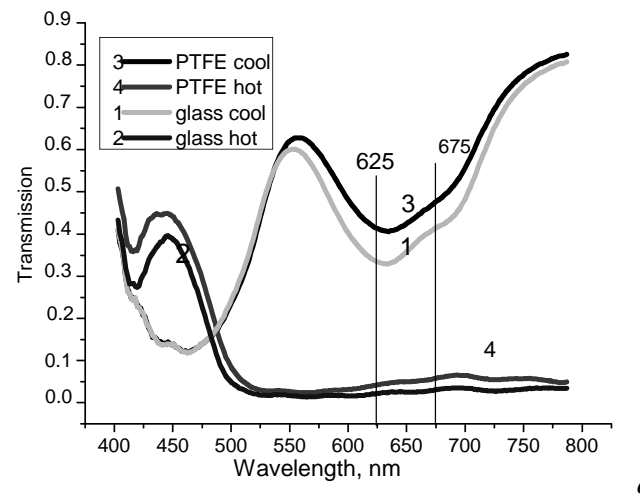

a)

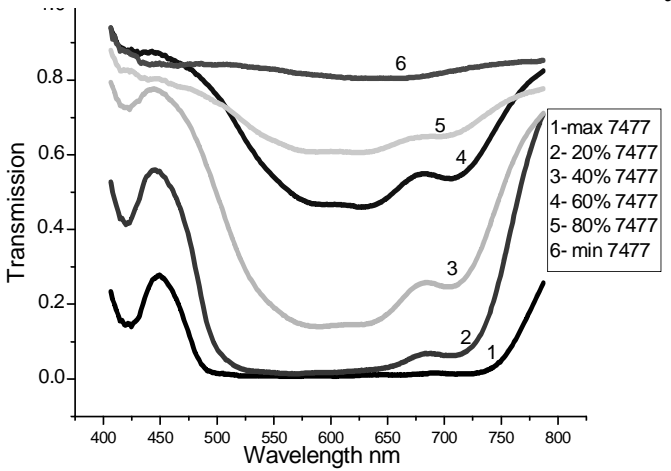

b)

Fig. 4. Optical spectra of 7477 PMD: (a) by influence of substrate material and its temperature; (b) dye in PTFE matrix.

Both substrate heating and coating it with PTFE film lead to formation of aggregated well organized film (Fig. 3b), while PTFE matrix keeps 2403 dye molecules in the monomeric state.

This film exhibited absorption bands with the peaks located at 670 and $560 \mathrm{~nm}$. Compared to the absorption of its solution, the absorption of the film is red-shifted 


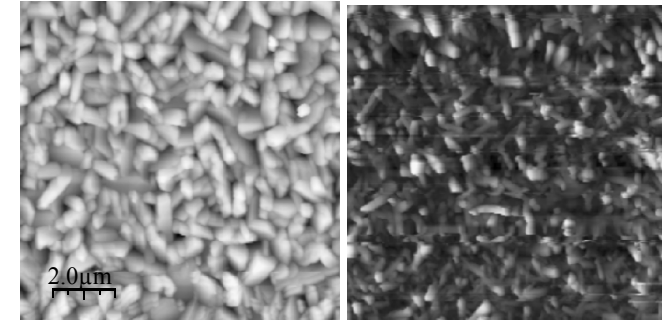

$$
\begin{array}{rr} 
& 7477 \text { on oriented PTFE } \\
20^{\circ} \mathrm{C} & 70^{\circ} \mathrm{C}
\end{array}
$$

Fig. 5. AFM images of the surface inherent to 7477 films, corresponding to spectra 7477 in Fig. 4a.

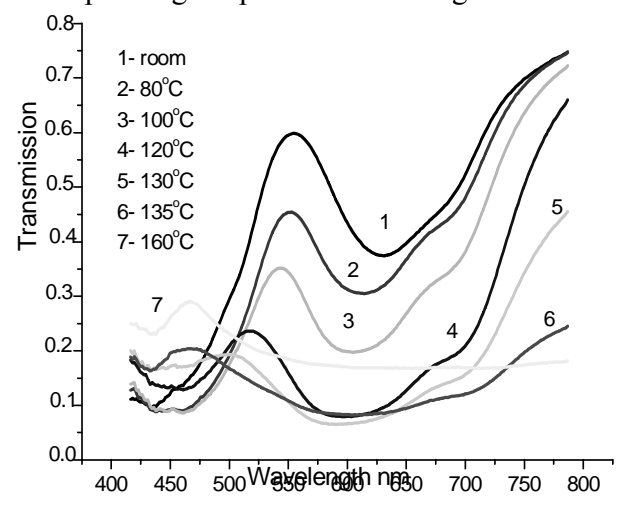

a)

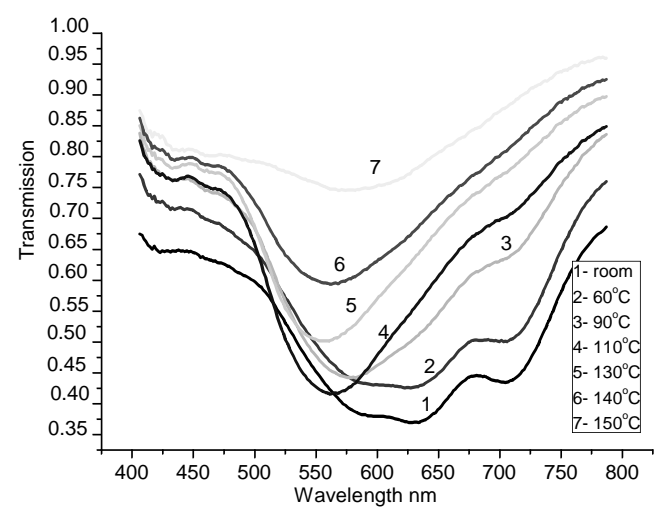

b)

Fig. 6. Spectra recorded during heating of 7477 dye film on glass: (a) deposited at room temperature; (b) dye in PTFE matrix.

by 35 to $145 \mathrm{~nm}$. It indicates that J-like aggregates were formed in the films. These aggregates are very important for application in nonlinear optics [8-10].

Optical spectra of the 7477 PMD are presented in Fig. 4. It is clearly seen that only temperature of growth strongly influences optical properties of the films. The phase formed at room temperature has three maxima at 460,620 and $695 \mathrm{~nm}$. The phase formed at $70 \mathrm{eC}$ is characterized with strong absorption in $500-800 \mathrm{~nm}$ range with the separate band at $420 \mathrm{~nm}$. 7477 PMD film morphology is presented in Fig. 5. The film grown at $70 \mathrm{\epsilon C}$ shows larger structural units. Deposition of 7477 PMD in the PTFE matrix at room temperature leads to formation of films with properties almost the same as those in the high temperature phase at high dye concentrations and intermediate at low dye concentrations. PTFE matrix shifts phase equilibrium. Fig. 6 presents spectra recorded in the course of heating the 7477 dye film (deposited at room temperature) and dye in PTFE matrix. The pure dye film transforms its structure from low- to high-temperature phase. Transformation of 7477 PMD in PTFE matrix is not the same as for pure dye, and the additional band at $525 \mathrm{~nm}$ appeared.

Because films have higher surface flatness and better thickness homogeneity than those of solutioncoated films, and their thickness are precisely controllable, these thin films of dyes are indispensable for fabricating many optical and electrooptic devices.

\section{Conclusions}

The influence of substituents in rows of polymethine dyes on kinetics of solid film growth and their structure was found. The influence of the substrate type, growth temperature and polytetrafluoroethylene matrix on dye film properties was determined. Some new dyes showed reversible optical transitions, which can be used in advanced optoelectronic devices.

\section{Acknowledgements}

Work was made in the frame of Project No 52 of Ukrainian State Program "Nanostructured systems, nanomaterials, nanotechnologies" and BMBF 08/018.

\section{References}

1. A.A. Ishchenko, Structure and Spectral-luminescent Properties of Polymethine Dyes. Kyiv, Naukova dumka, 1991, pp. 8-12, 189-206 (in Russian).

2. H. Bottcher, T. Fritz, J. Wright, Fabrication of evaporated dye films and application // J. Mater. Chem. 3, p. 1187-1196 (1993).

3. S.R. Forrest, Ultrathin organic films grown by organic molecular beam deposition and related techniques // Chem. Rev. 97(3), p. 1793-1896 (1997).

4. K. Grytsenko, T. Doroshenko, Yu. Kolomzarov, D. Prescher et al., Research on the growth of dye film in vacuum in situ // Proc. SPIE 6999 (2008).

5. K.P. Grytsenko, S. Schrader, Nanoclusters in polymer matrices prepared by co-deposition from a gas phase // Advances in Colloid and Interface Sci. 116, p. 263-276 (2005).

6. K. Grytsenko, Growth mechanism, properties and applications of vacuum-deposited PTFE films // Russian J. Chem. Soc. LII(3), p. 112-123 (2008).

7. K. Grytsenko, Yu. Kolomzarov, O. Lytvyn, V. Prokopets, O. Tolmachev et al., Nonconventional properties of dye clusters in polytetrafluoroethylene matrix // Abstr. Book Conf. "Physics and technol. of thin films and nanosystems," May 2529, Ivano-Frankivsk, Ukraine, p. 163-164 (2009). 